\title{
Food Consumption in Adults on the Basis of Dietary Surveys in European Countries
}

\author{
Food Consumption in Adults on the Basis of the EFSA Concise Food Consumption \\ Database (EFSA)
}

To date, numerous countries have collected data on individual food consumption from dietary surveys. The assessment of food consumption on the basis of representative dietary surveys as it was done by the EFSA Concise Food Consumption Database has several advantages compared to the use of the FAO Food Balance Sheets (FBS). Food supply as calculated from FBS overestimates food intake. Moreover, FBS do not consider the variability of consumption between individuals (cf. chapter 4).

Up to now, there is no fully harmonized European database on individual food consumption. Hence, the European Food Safety Authority (EFSA) has compiled the available data in order to make it as comparable as possible across Europe. For this purpose, expert members of the participating countries were asked to re-codify their latest and most appropriate dietary survey according to harmonized guidelines. The new EFSA Concise Database is intended for conservative estimates of exposure. Data are available for total population as well as for consumers only. Data for total population are of interest for this report. Consumption data is expressed as daily consumption per capita in grams. At this point, data are available for adults aged 16-64 years only. It is a future goal to create a database that is more comprehensive and provides data for specific population groups (e.g. children, elderly).

To overcome the problem of inhomogeneous categorization, EFSA has created a system using 15 broad food categories. Examples of foods enable a definite assignment to a particular food group. Foods that unmistakably belong to a category were not mentioned in the list of examples (table 6.1).

The consistency of the consumption data was verified by requesting daily energy intake for each individual. Additionally, no exclusion of under-reporters was applied, as the methodologies for this purpose are not yet harmonized across the participating countries [EFSA, 2008a]. However, the methods used, as well as age groups and duration of surveillance, are still inhomogeneous in this compilation (table 6.2). Several countries 
Table 6.1. 15 broad food categories as used in the Concise Database (Foods that unmistakably belong to a particular category are not mentioned here)

\begin{tabular}{|c|c|c|c|}
\hline \multicolumn{3}{|c|}{ Food category } & \multirow{2}{*}{$\begin{array}{l}\text { Examples of items } \\
\text { muesli bars, biscuits, fried rice, buckwheat, quinoa, cereal-based snacks, } \\
\text { popcorn, couscous, paella, pizza, sandwiches, lasagna, quiches, salt cake, } \\
\text { pancakes, spring rolls } \\
\text { Remark: preferably expressed as raw cereals }\end{array}$} \\
\hline 1 & $\begin{array}{l}\text { Cereals and cereal } \\
\text { products }\end{array}$ & solid & \\
\hline 2 & $\begin{array}{l}\text { Sugar and sugar products } \\
\text { including chocolate }\end{array}$ & solid & $\begin{array}{l}\text { jam, marmalade, honey, toppings, chewing gum, toffees, fudges, chocolate, } \\
\text { candies, chocolate confectionery, liquorice, marzipan, sugar-free confectionary, } \\
\text { cocoa powder, meringue, nutritive sweeteners (e.g. fructose) } \\
\text { List of items excluded: intense sweeteners }\end{array}$ \\
\hline 3 & $\begin{array}{l}\text { Fats (vegetable and } \\
\text { animal) }\end{array}$ & solid & $\begin{array}{l}\text { mayonnaise, dressings, sauces (béchamel, hollandaise), low-fat dressings or } \\
\text { mayonnaise, goose fat, coconut extract } \\
\text { List of items excluded: vegetable sauces }\end{array}$ \\
\hline 4 & $\begin{array}{l}\text { Vegetables, nuts, } \\
\text { pulses including carrots, } \\
\text { tomatoes and leafy } \\
\text { vegetables }\end{array}$ & $\begin{array}{l}\text { solid/ } \\
\text { liquid }\end{array}$ & $\begin{array}{l}\text { cooked and raw products, vegetable sauces (tomato sauce, ketchup), vegetable } \\
\text { condiments, vegetable soup, snack nuts, olives, capers, chestnuts, rhubarb, } \\
\text { soy-based products (excl. milk), coconuts, peanut butter, avocado, quorn, tofu } \\
\text { List of items excluded: starchy roots } \\
\text { Remark: preferably expressed as raw vegetable; dehydrated soups expressed } \\
\text { as such }\end{array}$ \\
\hline 5 & Starchy roots or potatoes & solid & $\begin{array}{l}\text { tapioca, cassava, sweet potatoes, starch/potato-based crisps } \\
\text { List of items excluded: carrots }\end{array}$ \\
\hline 6 & Fruits & solid & $\begin{array}{l}\text { dried fruits, canned fruit, fruit mousse, compote } \\
\text { List of items excluded: fruit juice }\end{array}$ \\
\hline 7 & $\begin{array}{l}\text { Fruit and vegetable juices, } \\
\text { soft drinks and bottled } \\
\text { water }\end{array}$ & liquid & \\
\hline 8 & $\begin{array}{l}\text { Coffee, tea, cocoa } \\
\text { (expressed as liquid) }\end{array}$ & liquid & $\begin{array}{l}\text { ice coffee, herbal tea (infusion), water-based cocoa beverage } \\
\text { List of items excluded: ice tea, milk-based chocolate }\end{array}$ \\
\hline 9 & Alcoholic beverages & liquid & \\
\hline 10 & $\begin{array}{l}\text { Meat and meat products, } \\
\text { offal }\end{array}$ & solid & \\
\hline 11 & Fish and seafood & solid & fish eggs \\
\hline 12 & Eggs & solid & $\begin{array}{l}\text { omelette, fried eggs } \\
\text { List of items excluded: fish eggs }\end{array}$ \\
\hline 13 & $\begin{array}{l}\text { Milk- and diary-based } \\
\text { products }\end{array}$ & $\begin{array}{l}\text { solid/ } \\
\text { liquid }\end{array}$ & cold milk chocolate, soy milk \\
\hline 14 & $\begin{array}{l}\text { Miscellaneous/food for } \\
\text { special dietary uses }\end{array}$ & solid & $\begin{array}{l}\text { salt, baker's yeast, vinegar, mustard, condiment sauce (e.g. sweet-sour sauce, } \\
\text { soy sauce), herbs and spices, pepper, gelatine, intense sweeteners, fat-free } \\
\text { sauces, glutamate-based products (e.g. vetsin, marmite)/meal substitutes, food } \\
\text { for special purposes, food supplements (e.g. fish oil, vitamins, brewers'yeast) } \\
\text { List of items excluded: nutritional sweeteners (e.g. fructose) }\end{array}$ \\
\hline 15 & Tap water & liquid & \\
\hline
\end{tabular}

Source: EFSA, 2008b. 
Table 6.2. Age group, method and year(s) of survey - overview of 16 countries

\begin{tabular}{llll}
\hline Country & Age group, years & Method & Year(s) of survey \\
\hline Austria & $19-64$ & 24-hour recall & 2005-2006 \\
\hline Belgium & $16-64$ & 24-hour recall & 2004 \\
\hline Czech Republic & $16-64$ & 24-hour recall & 2003-2004 \\
\hline Denmark & $4-65$ & 7-day precoded food & 2000-2002 \\
\hline Estonia & $16-64$ & diary with open fields & 1997 \\
\hline Finland & $25-64$ & 24-hour recall & 2002 \\
\hline France & $>14$ & 48-hour recall & 1999 \\
\hline Germany & $>17$ & 7-day dietary record & 1998 \\
\hline Hungary & $>17$ & 28-day dietary history & 2003-2004 \\
\hline Ireland & $18-64$ & 3-day dietary record & $1997-1999$ \\
\hline Italy & $16-64$ & 7-day dietary record & $1994-1996$ \\
\hline Netherlands & all ages & 7-day dietary record & $1997-1998$ \\
\hline Norway & $16-79$ & 2-day dietary record & $1993-1997$ \\
\hline Poland & 1-96 & $\begin{array}{l}\text { quantitative food frequency } \\
\text { questionnaire }\end{array}$ & 2000 \\
\hline Sweden & $>16$ & 24-hour recall & 2000-2001 \\
\hline UK & $19-64$ & 7-day dietary record & 7-day dietary record \\
\hline
\end{tabular}

Source: EFSA, 2008b.

provided data for participants $<16$ and/or $>64$ years. If that was the case, only participants aged 16-64 years were included. It has to be noted that differences between countries can be caused by different survey methodologies or different durations of survey.

In 7 of 15 food categories, highest consumption was reported in Poland. To some extent, this might be caused by inhomogeneous methodology across the compared studies. The high level of consumption in Poland might be linked to two important issues. The first one is the time of data collection - the Polish survey was conducted in the peak season of fruit, vegetable, and potato consumption. The second issue relates to the demographical structure in Poland, that implies a high level of food self-supply, since $40 \%$ of the Polish population lives in rural areas. Another limitation is the diverging assignment of foods to the food groups due to the use of differing nutritional evaluation software. For instance, ingredients- vs. recipe- 
Table 6.3. Average consumption and countries with highest and lowest consumption of 15 broad food groups (g/capita/day)

\begin{tabular}{|c|c|c|c|c|}
\hline & $\begin{array}{l}\text { Countries } \\
\mathrm{n}\end{array}$ & Mean & Min (country) & Max (country) \\
\hline Cereals and cereal products & 16 & 277 & 153 (Finland) & 330 (Austria) \\
\hline $\begin{array}{l}\text { Sugar and sugar products including } \\
\text { chocolate }\end{array}$ & 16 & 36 & 20 (Italy) & 57 (Poland) \\
\hline Fats (vegetable and animal) & 16 & 34 & 12 (Austria) & 60 (Poland) \\
\hline $\begin{array}{l}\text { Vegetables, nuts, pulses including carrots, } \\
\text { tomatoes and leafy vegetables }\end{array}$ & 16 & 220 & 118 (Sweden) & 295 (Poland) \\
\hline Starchy roots or potatoes & 16 & 119 & 48 (Italy) & 304 (Poland) \\
\hline Fruits & 16 & 166 & 95 (UK) & 282 (Poland) \\
\hline $\begin{array}{l}\text { Fruit and vegetable juices, soft drinks } \\
\text { and bottle water }\end{array}$ & 16 & 495 & 179 (Ireland) & 947 (Germany) \\
\hline Coffee, tea, cocoa (expressed as liquid) & 16 & 521 & 124 (Italy) & 887 (Netherlands) \\
\hline Alcoholic beverages & 16 & 195 & 68 (Poland) & 413 (Czech Republic) \\
\hline Meat and meat products, offal & 16 & 174 & 109 (Norway) & 259 (Poland) \\
\hline Fish and seafood & 16 & 28 & 9 (Hungary) & 63 (Norway) \\
\hline Eggs & 16 & 20 & 5 (Austria) & 31 (Poland) \\
\hline Milk- and dairy-based products & 16 & 266 & 171 (Austria) & 522 (Norway) \\
\hline Miscellaneous/food for special dietary uses & 16 & 15 & 2 (Belgium) & 36 (Germany) \\
\hline Tap water & 13 & 225 & 71 (Germany) & 887 (Finland) \\
\hline
\end{tabular}

Means were calculated as arithmetic averages weighted for total country populations of adults aged 15-64 years at the year of survey.

Source: Eurostat, 2009.

$\mathrm{n}$ (subjects) $=33,463$ (total number of subjects that participated in the surveys of the 16 countries).

Source of raw data: EFSA, 2008b.

based processing yields inconsistent results. Further information on the strengths and limitations of the EFSA Concise Database can be found on the website: http:// www.efsa.europa.eu/EFSA/ScientificPanels/DATEX/efsa_locale-1178620753812_ ConciseEuropeanConsumptionDatabase.htm.

With the exception of tap water (no data from Estonia, Hungary, and Poland), data are available from 16 of the participating countries of the ENHR 2009 for the 15 broad food categories. Countries with the highest and lowest intake as well as mean values are compiled in table 6.3. Means were calculated as arithmetic averages and 
weighted for the total country populations of adults aged 15-64 years at the year of survey [Eurostat, 2009].

The amounts of consumption of the 15 broad food categories in the four predefined ENHR 2009 regions are described below (means of the countries belonging to a region weighted on the basis of total country populations at the year of survey). Denmark, Estonia, Finland, Norway, and Sweden represent the North region; Austria, the Czech Republic, Germany, Hungary, and Poland represent the Central and East region; Belgium, France, Ireland, The Netherlands, and the UK represent the West region; Italy represents the South region.

Cereals and Cereal Products. The highest consumption of this food group was reported in the Central and East region (292 g/capita/day). The North region (223 g/ day) was far below the average of the regions. Especially the countries Austria (330 g/day), France (318 g/day), and Poland (312 g/day), reported high amounts of cereal intake. The lowest values were accounted for Finland (153 g/day), Estonia (186 g/ day), and Norway (182 g/day).

Sugar and Sugar Products, Including Chocolate. The Central and East region had the highest intake of sugar and sugar products ( $46 \mathrm{~g} / \mathrm{capita} /$ day). In the South region, represented only by Italy, less than half of this quantity was reported (20 g/day). Poland (57 g/day), Norway (47 g/day), and Germany (45 g/day) were the countries with the highest values. In addition to Italy ( $20 \mathrm{~g} /$ day), Estonia (21 g/day) and Austria ( $23 \mathrm{~g} /$ day) had satisfyingly low results in this category.

Fats (Vegetable and Animal). As for sugar and sugar products, the highest intake of fats was reported in the Central and East region (39 g/capita/day). The lowest values were reported in the West region ( $28 \mathrm{~g} /$ day). The other three regions were positioned around 35 g/day. Poland (60 g/day), Hungary (54 g/day), and The Netherlands (48 g/ day) were the countries with the highest values. The lowest consumption was reported in Austria (12 g/day), the UK (20 g/day), and Sweden (24 g/day).

Vegetables, Nuts, Pulses Including Carrots, Tomatoes and Leafy Vegetables. Consumption of foods belonging to this category was very high in the South ( $249 \mathrm{~g} /$ capita/day) and Central and East regions (248 g/day). The North region (140 g/day) was far below the average. The highest values appeared in Poland (295 g), Germany (252 g/day), and Italy (249 g/day). Lowest values were reported in Sweden (118 g/day), the Czech Republic (131 g/day), and Finland (135 g/day).

Starchy Roots or Potatoes. The consumption of starchy roots and potatoes was highest in the Central and East region (165 g/capita/day), followed by the North (126 $\mathrm{g} /$ day) and West regions (97 $\mathrm{g} /$ day). The value for the South region was exceptionally low (48 g). Besides an extraordinarily high result for Poland (304 g/day), high values were reported in Ireland ( $229 \mathrm{~g} /$ day) and Estonia (201 g/day). In addition to Italy (48 g/day), Austria ( $59 \mathrm{~g} /$ day) and France (67 g/day) had the lowest values.

Fruits. It is recommended to consume at least five servings of a variety of fruits and colorful vegetables each day [WCRF/AIRC, 2007]. The sum of fruits and vegetables should exceed $400 \mathrm{~g} /$ day [Kushi et al., 2006]. 
The highest intake of fruits was reported in the Central and East (209 g/capita/ day) and South regions (203 g/day). Fruit consumption was considerably lower in the North (129 g/day) and West regions (113 g/day). Leading countries concerning the consumption of fruits were Poland (282 g/day), Italy (203 g), and Austria (202 g/day). The lowest values were assessed for the UK (95 g/day), Ireland (106 g/day), and The Netherlands (107 g/day). On average, only four countries (Poland, Germany, Italy, and Austria) have met the recommendation of consuming at least $400 \mathrm{~g}$ of fruits and vegetables per day.

Fruit and Vegetable Juices, Soft Drinks and Bottled Water. The consumption of products belonging to this category was highest in the Central and East region $(667 \mathrm{~g} /$ capita/day). The lowest values emerged in the North region (331 g/day). Remarkably high values were accounted for Germany ( $947 \mathrm{~g} /$ day) and Belgium (945 g/day), followed by the Czech Republic ( $618 \mathrm{~g} /$ day). The lowest intake was found to be in Ireland (179 g/day), Finland (213 g/day), and Poland (237 g/day).

Coffee, Tea, Cocoa (Expressed as Liquid). The Central and East (633 g/capita/day) and North regions ( $625 \mathrm{~g} /$ day) had the highest values in this category. In contrast, only $124 \mathrm{~g} /$ day were accounted in the South region. The highest consumption was reported in The Netherlands ( $887 \mathrm{~g} /$ day), Denmark ( $836 \mathrm{~g} /$ day), and the UK (725 g/ day). In addition to Italy ( $124 \mathrm{~g} /$ day), Hungary ( $176 \mathrm{~g} /$ day) and France ( $282 \mathrm{~g} /$ day) had the lowest values in this category.

Alcoholic Beverages. The highest consumption of alcoholic beverages was reported in the West region (235 g/capita/day), whereas the lowest values appeared in the South region (126 g/day). The North and Central and East regions showed an equal result (181 g). The Czech Republic (413 g/day), Ireland ( $335 \mathrm{~g} /$ day), and the UK (313 $\mathrm{g} /$ day) were the countries with the highest consumption of alcoholic beverages. The lowest values were reported in Poland (68 g/day), Hungary ( $76 \mathrm{~g} /$ day), and Austria (118 g/day).

Meat and Meat Products, Offal. The consumption of meat and meat products was higher in the Central and East region (194 g/capita/day) than in the West (174 g/day), South (137 g/day), and North regions (134 g/day). The highest values were reported in Poland (259 g/day), France ( $202 \mathrm{~g} /$ day), and the Czech Republic (187 g/day). The lowest intake appeared in Norway (109 g/day), Finland (120 g/day), and Belgium (123 g/day).

Fish and Seafood. The highest consumption of fish and seafood was found in the South region ( $43 \mathrm{~g} / \mathrm{capita} /$ day). As the Central and East region $(18 \mathrm{~g} /$ day) is predominantly represented by landlocked countries, the low intake emerged as expected. An outstandingly high consumption was reported in Norway (63 g/day), followed by Italy ( $43 \mathrm{~g} /$ day) and France ( $37 \mathrm{~g} /$ day). On the other hand, intake of fish and seafood was exceptionally low in Hungary ( 9 g/day) and still lower in The Netherlands (13 g/ day) and Austria (16 g/day).

Eggs. Consumption of eggs was found to be highest in the Central and East region ( $25 \mathrm{~g} /$ capita/day), followed by the South (18 g/day), West (18 g/day), and North 


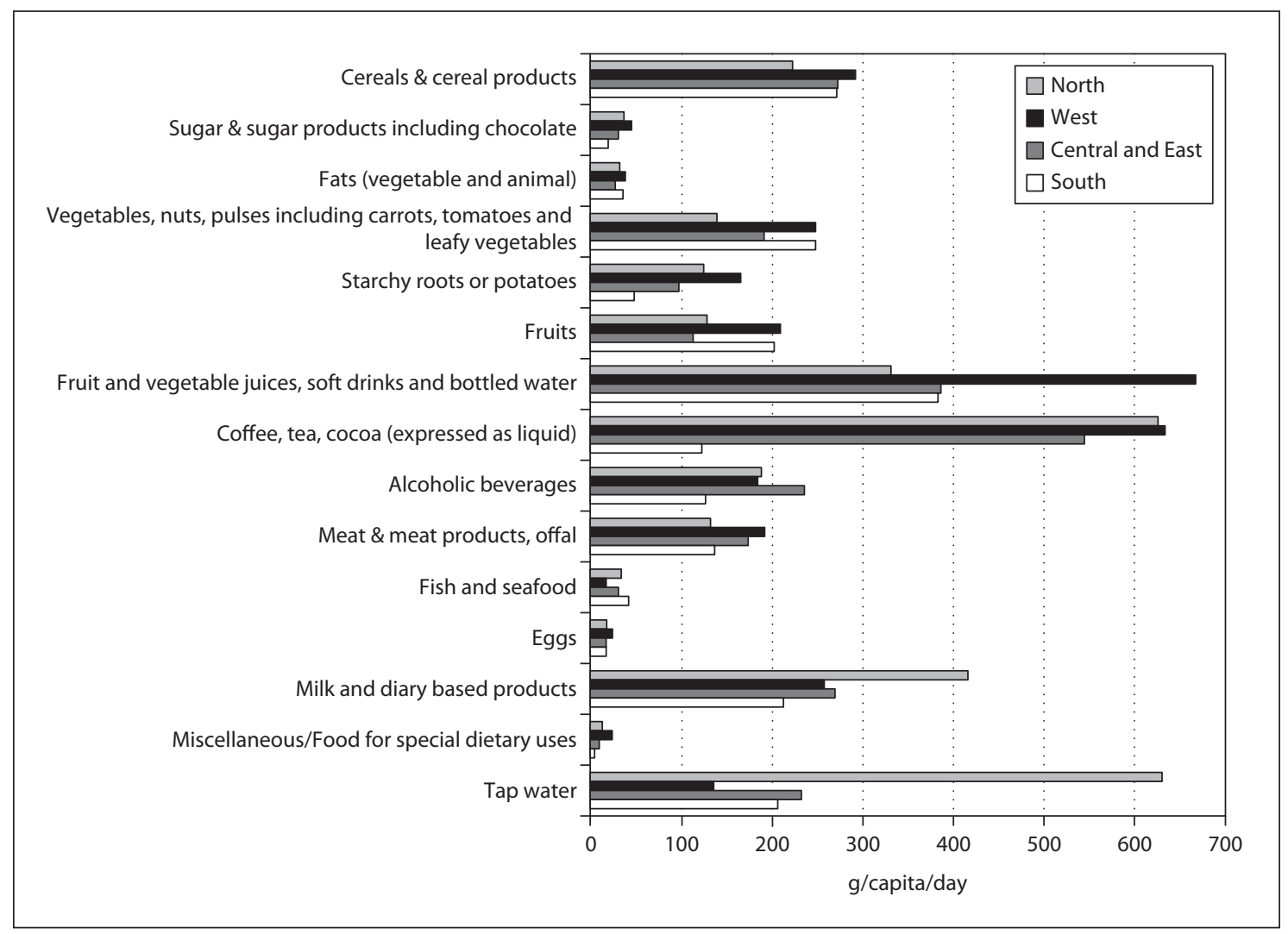

Fig. 6.1. 15 broad food categories - comparison of the four regions of ENHR 2009. Means were calculated as arithmetic averages weighted for total country populations of adults aged 15-64 years in the year of survey. Source: Eurostat, 2009.

regions (17 g/day). The countries Poland ( $31 \mathrm{~g} /$ day), Hungary (27 g/day), and Estonia ( $27 \mathrm{~g} /$ day) had the highest intake of eggs. The lowest values appeared in Austria (5 g/ day), followed by Belgium (10 g/day), and Sweden (14 g/day).

Milk- and Dairy-Based Products. The highest consumption of milk- and dairybased products was reported in the North region ( $416 \mathrm{~g} /$ capita/day). The lowest intake was found in the South region (212 g/day). Norway (522 g/day), Finland (437 g/day), and The Netherlands (388 g/day) were the countries with the highest values in this category. Intake was low in Austria (171 g/day), Poland (181 g/day), and the Czech Republic (186 g/day). Concerning the high intake of milk- and dairy-based products in the northern parts of Europe, it has to be considered that lactose intolerance is less prevalent in this area [EUFIC, 2006].

Miscellaneous/Food for Special Dietary Uses. In this category, highest amounts were accounted for the Central and East region (25 g/capita/day). The lowest values were reported in the South region ( $5 \mathrm{~g} /$ day). The countries with the highest consumption 
were Germany ( $36 \mathrm{~g} /$ day), Finland ( $24 \mathrm{~g} /$ day), and the UK (12 g/day). The lowest results appeared in Belgium ( $2 \mathrm{~g} /$ day), France ( $2 \mathrm{~g} /$ day), and Estonia ( $\mathrm{g}$ /day).

Tap Water. It is recommended to drink at least eight cups of liquid (equal to $1,000-1,500 \mathrm{~g}$ ) per day. More can be beneficial. A sufficient fluid intake requires 21 of water per day [WCRF/AIRC, 2007], or $30 \mathrm{ml} / \mathrm{MJ}$ of consumed food energy [Eurodiet, 2000]. The results shown here refer to the consumption of tap water only.

The differences concerning tap water consumption were relatively small between the West $(231 \mathrm{~g} /$ capita/day) and South regions (206 g/day). Tap water intake was highest in the North region $(630 \mathrm{~g} /$ day) and lowest in the Central and East region (136 g/day). The highest consumption was reported in Finland (887 g/day), Denmark (840 g/day), and Austria (594 g/day). For Germany (71 g/day) and Belgium (100 g/ day) the lowest results emerged.

Figure 6.1 shows an overview of the consumption of the 15 broad food categories in the four regions of ENHR 2009. Means were calculated as arithmetic averages weighted on the basis of the total age-specific population of the countries. 